\title{
Endocannabinoid system: Role in depression, reward and pain control (Review)
}

\author{
WEN-JUAN HUANG, WEI-WEI CHEN and XIA ZHANG \\ Department of Neurology, Xuzhou Central Hospital, Xuzhou, Jiangsu 221009, P.R. China
}

Received May 17, 2016; Accepted July 25, 2016

DOI: $10.3892 / \mathrm{mmr} .2016 .5585$

\begin{abstract}
Depression and pain co-exist in almost $80 \%$ of patients and are associated with impaired health-related quality of life, often contributing to high mortality. However, the majority of patients who suffer from the comorbid depression and pain are not responsive to pharmacological treatments that address either pain or depression, making this comorbidity disorder a heavy burden on patients and society. In ancient times, this depression-pain comorbidity was treated using extracts of the Cannabis sativa plant, known now as marijuana and the mode of action of $\Delta^{9}$-tetrahydrocannabinol, the active cannabinoid ingredient of marijuana, has only recently become known, with the identification of cannabinoid receptor type 1 (CB1) and $\mathrm{CB} 2$. Subsequent investigations led to the identification of endocannabinoids, anandamide and 2-arachidonoylglycerol, which exert cannabinomimetic effects through the $\mathrm{CB} 1$ and $\mathrm{CB} 2$ receptors, which are located on presynaptic membranes in the central nervous system and in peripheral tissues, respectively. These endocannabinoids are produced from membrane lipids and are lipohilic molecules that are synthesized on demand and are eliminated rapidly after their usage by hydrolyzing enzymes. Clinical studies revealed altered endocannabinoid signaling in patients with chronic pain. Considerable evidence suggested the involvement of the endocannabinoid system in eliciting potent effects on neurotransmission, neuroendocrine, and inflammatory processes, which are known to be deranged in depression and chronic pain. Several synthetic cannabinomimetic drugs are being developed to treat pain and depression. However, the precise mode of action of endocannabinoids on different targets in the body and whether their effects on pain and depression follow the same or different pathways, remains to be determined.
\end{abstract}

Correspondence to: Dr Wen-Juan Huang, Department of Neurology, Xuzhou Central Hospital, 199 Jiefang South Road, Xuzhou, Jiangsu 221009, P.R. China

E-mail: ftmlb8556215@163.com

Key words: depression, endocannabinoids, anandamide, 2-arachidonoylglycerol

\section{Contents}

1. Introduction

2. The endocannabinoid system

3. Endocannabinoids in pain and depression

4. Conclusions

\section{Introduction}

The most common debilitating disorders affecting society at large are pain and depression, which are the most prevalent among neurological and psychiatric disorders. Depression and pain co-exist in almost $80 \%$ of patients (1) and are associated with impaired health-related quality of life, often contributing to high mortality $(2,3)$. It has been observed that patients suffering from inflammatory and neuropathic pain are almost 5 times more prone to develop depression or anxiety disorder as compared to the general population (4-6). However, the majority of patients who suffer from comorbid depression and pain are not responsive to pharmacological treatments that address the pain or depression, making this comorbidity disorder a heavy burden on patients and society (7). These clinical observations on the association of pain and depression have been confirmed in several animal models of depression and chronic pain based on genetics, stress, lesion, and pharmacological manipulation that show altered nociceptive response $(8,9)$. Considering the significance of the complex interaction between pain and depression and its societal impact, a better understanding of the molecular basis for this association is needed for developing more effective therapeutics.

In ancient times, this depression-pain comorbidity was treated through the use of extracts of the Cannabis sativa plant, commonly known now as marijuana. Use of marijuana for addressing pain due to various reasons has become a hot topic in terms of possible addiction, drug abuse as well as regulatory issues. Although historically, the use of marijuana dates back to over $2000 \mathrm{BC}$, the biological action of the main psychoactive ingredient of marijuana, $\Delta^{9}$-tetrahydrocannabinol $\left(\Delta^{9}\right.$-THC) has only recently been identified. The biological receptor of $\Delta^{9}$-THC on the cell surface has recently been identified and described $(10,11)$. Characterization of this receptor led to understanding of the mode of action of $\Delta^{9}$-THC that underlies its wide spectrum of pharmacological effects, which encompass euphoria, calmness, appetite stimulation, sensory 
alterations and analgesia $(10,11)$. Identification of the first endogenous cannabinoid-like substance, anandamide, in pig brain reiterated the significance of the so-called cannabinoid receptor and its endogenous ligands in the control of a wide variety of biological activities (12). The name 'anandamide', derived from Sanskrit ('ananda' meaning bliss) is given to $\mathrm{N}$-arachidonoylethanolamine, for its cannabinomimetic effects. Another endogenous cannabinomimetic compound known as 2 -arachidonoylglycerol $(2-A G)$ was identified $(13,14)$. Of note, the two endocannabinoids were derivatives of arachidonic acid. Considering that these compounds are cannabinomimetic and endogenous, acting on the cannabinoid receptors, they are known as endocannabinoids.

\section{The endocannabinoid system}

Besides anandamide and 2-AG, there are other endogenously produced molecules that also likely influence the function of CB receptors. These molecules include oleamide (15), O-arachidonoyl ethanolamine, also termed virodhamine (16), 2-AG ether or noladin ether (17), and $\mathrm{N}$-arachidonoyldopamine (18). However, their physiological role is not clear and thus whether they are true endocannabinoids has yet to be ascertained. In addition to $\Delta^{9}$-THC, almost 80 other phytocannabinoids are found in the cannabis extracts, with a structure similar to that of THC. Of these, THC is the most studied and was shown to activate cannabinoid receptor type 1 (CB1) and CB2 and affect many pathophysiological processes, including anti-nociception (19). However, because of its CB1-mediated unwanted CNS effects, the clinical utility of THC is limited (19). Subsequent studies revealed that another phytocannabinoid, cannabidiol, with very low affinity to bind to $\mathrm{CB} 1$ and $\mathrm{CB} 2$ receptors, exerts positive pharmacological effects, such as anti-anxiety, anti-epileptic, anti-bacterial, anti-inflammatory, anticancer and also anti-diabetic properties without any psychoactivity (20). Nabiximols, a cannabis extract containing THC and cannabidiol at a 1:1 ratio, has been approved for the treatment of neuropathic pain, spasticity associated with multiple sclerosis and intractable cancer pain (21). In addition to the natural cannabinoids, synthetic cannabinoids, such as dronabinol, and its analogue nabilone, have been developed to address various types of pain. For instance, dronabinol and nabilone are currently used for chemotherapy-associated emesis in Canada and USA and nabilone is indicated for anorexia associated with AIDS-related weight loss (22). In addition, findings of a clinical trial showed the efficacy of nabilone in diabetic neuropathy (23). Another synthetic drug, an antagonist/inverse agonist of CB1 receptor, rimonabant, initially approved for obesity and smoking cessation, was found to have depressive effects and was subsequently withdrawn.

Biosynthesis of endocannabinoids. Endocannabinoids are lipophilic molecules synthesized 'on demand' from membrane phospholipids, and released immediately, without storage in vesicles. Anandamide and 2-AG are produced at post-synaptic neurons. Anandamide is produced in a two-step process involving $N$-arachidonoylation of the membrane phospholipid, phosphatidylethanolamine, to form $\mathrm{N}$-arachidonoyl phosphatidylethanolamine (NAPE) by a calcium-dependent $N$-acyltransferase, followed by hydrolysis

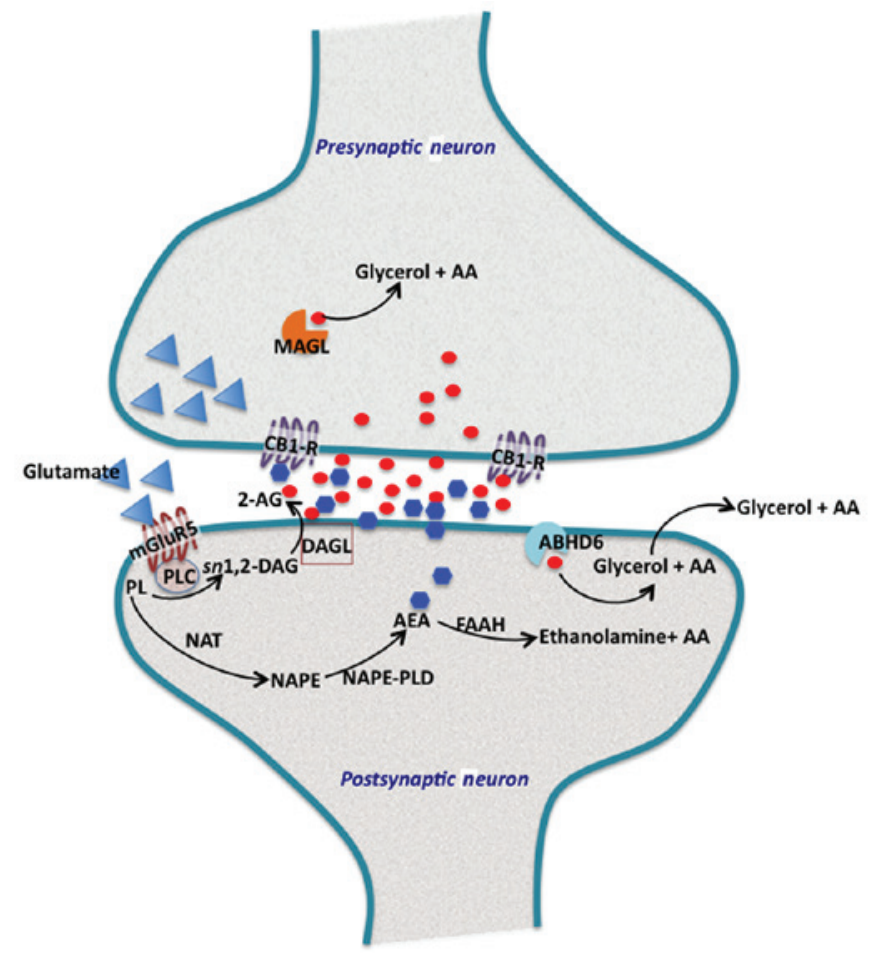

Figure 1. Endocannabinoid biosynthesis and signalling at synapse. In the perisynaptic zone of the dendritic spine, the three main proteins involved in 2-arachidonoylglycerol (2-AG) production are located in the postsynaptic neurons $(28,29)$. Activation of mGluR5 metabotropic glutamate receptors, leads to the hydrolysis of membrane phosphatidylinositols (PL) by phospholipase C (PLC)- $\beta$ to form sn1,2-diacylglycerol (sn1,2-DAG), which contains arachidonic acid at position-2. The sn1,2-DAG is then hydrolyzed by plasma membrane bound to DAG lipase- $\alpha$ (DAGL), to generate 2-AG. The concerted action of these protein components located proximal to each other on the postsynaptic membrane, allows for the rapid accumulation of 2-AG. 2-AG then enters the the synaptic cleft to activate cannabinoid receptor type 1 (CB1), present on the presynaptic axon terminals. 2-AG that reaches into presynaptic terminals, is hydrolyzed by monoacylglycerol lipase (MAGL). Excess 2 -AG in the postsynaptic terminals is degraded by $\alpha / \beta$ hydrolase domain containing 6 (ABHD6), which is a MAG hydrolase. By contrast, arachidonoylethanolamine or anandamide (AEA) is also produced in the postsynaptic terminals by the action of $N$-acyltransferase, which synthesizes $\mathrm{N}$-arachidonoyl phosphatidylethanolamine (NAPE). NAPE is further hydrolyzed by a specific PLD (NAPE-PLD) to generate AEA. AEA also traverses the postsynaptic membrane and reaches the $\mathrm{CB} 1$ receptors at the presynaptic axon terminals. Most of the excess and unused AEA is rapidly eliminated in postsynaptic terminals by fatty acid amide hydrolase (FAAH).

by a NAPE-selective phospholipase D (NAPE-PLD) to form $\mathrm{N}$-arachidonoylethanolamine (anandamide) $(24,25)$. Anandamide levels are regulated by its breakdown through the action of fatty acid amide hydrolase (FAAH) (26). 2-AG is synthesized in a two-step process, in which diacylglycerol (DAG) is first produced by the PLC from inositol phospholipids, followed by the hydrolysis of DAG to 2-AG by plasma membrane-associated sn1-DAG lipase (DAGL) (14). Once formed, 2-AG levels are regulated by monoacylglycerol lipase (MAGL), which accounts for $\sim 85 \%$ of the hydrolysis and by $\alpha / \beta$ hydrolase domain containing 6 (ABHD6) and ABHD12, which also hydrolyze 2-AG to arachidonic acid and glycerol (27). In addition to hydrolysis, 2-AG is acted on by cyclooxygenase-2 (28) and lipoxygenase (29), to form prostaglandin glyceryl esters and other related bioactive compounds (Fig. 1). 
Table I. Cannabinoid-based therapies to treat pain and depression.

Outcomes for

\begin{tabular}{lccc} 
Condition & Cannabinoid-based drug & Outcomes for pain & depression and anxiety \\
\hline HIV & Marijuana & $\downarrow$ Muscle, nerve pain & $\downarrow$ Anxiety \\
Cancer & Nabilone & $\downarrow$ Pain score & $\downarrow$ Overall stress \\
Fibromyalgia & Nabilone & $\downarrow$ Pain & $\downarrow$ Anxiety \\
Offenders with & Nabilone & $\downarrow$ Pain & $\downarrow$ Post-traumatic stress \\
psychiatric disorders & & disorder symptoms \\
Chronic central neuropathic pain & $\Delta^{9}$-THC & $\downarrow$ Anxiety \\
Diabetic peripheral neuropathy & Sativex $\left(\Delta^{9}\right.$-THC, cannabidiol $)$ & $\downarrow$ Pain and pain intensity & $\uparrow$ Quality of life \\
\hline
\end{tabular}

$\Delta^{9}$-THC, $\Delta^{9}$-tetrahydrocannabinol.

Cannabinoidreceptors. Two subtypes of cannabinoid receptors, CB1 and CB2, have been cloned and characterized $(11,30)$. $\mathrm{CB} 1$ receptors are most abundant in the central nervous system (CNS), whereas CB2 receptors are present mostly in peripheral tissues with immune functions, and most densely in the spleen (31). In the CNS, CB1 receptors are distributed densely in motor and limbic regions, in areas involved in pain transmission and modulation (e.g., periaqueductal grey, rostral ventromedial medulla, and spinal cord dorsal horn), as well as in the periphery (32). In the synapses, CB1 receptors show pre-synaptic localization on axons and terminals of neurons. The CB1 and CB2 receptors are G-protein coupled receptors of $\mathrm{Gi} / \mathrm{Go}$ subtype, and mediate the inhibition of neurotransmitter release. Once released, endocannabinoids bind to $\mathrm{CB} 1$ receptors located in the presynaptic membrane. These $\mathrm{CB}$ receptors inhibit adenylate cyclase. Only CB1 receptor activation, but not that of $\mathrm{CB} 2$ receptors, causes blockage of voltage-dependent $\mathrm{N}$ - and $\mathrm{P} / \mathrm{Q}$-type calcium channels through the activation of potassium channels and mitogen-activated protein kinase. Although CB2 receptors are mostly localized in immune cells and peripheral tissues, their presence has been observed in some subsets of neurons in brain and thus these receptors likely participate in the modulation of neurotransmission (33). Endocannabinoids also bind to other receptors including transient receptor potential vanilloid 1, peroxisome proliferator-activated receptors, GPR55, and GPR119 (34-36) and this non-CB1/2 receptor activity of endocannabinoids accounts for the differential effects of certain cannabinoid agonists and pharmacological modulators of endocannabinoid tone.

Following activation of their receptors, endocannabinoids are removed from the synaptic junction/extracellular space by a process of cellular uptake and then their hydrolysis. It has been suggested that the uptake of anandamide is probably mediated via a specific 'endocannabinoid membrane transporter', which is yet to be identified $(37,38)$. It is not clear how 2-AG uptake is mediated. Anandamide is hydrolyzed in post-synaptic neurons by FAAH, thus terminating the anandamide action at the time of its synthesis, whereas 2-AG is hydrolyzed in pre-synaptic neurons by MAGL, following CB1 receptor activation. Metabolism of anandamide by lipoxygenase and cycloxygenase enzymes yields oxygenated products with activity on non-cannabinoid targets (39).

\section{Endocannabinoids in pain and depression}

Pain is an integrative experience that involves physiological, emotional and cognitive aspects and this experience varies among individuals. Laboratory animals, on which most of basic pain research is conducted, cannot report pain and in animals, pain is generally monitored by differentiating between the subjective experience and nociception, the measurable neuronal events underlying the pain (?). Nociceptive pathways are triggered by the transduction of noxious stimuli, such as heat and mechanical injury, into neuronal action potentials by sensory afferent neurons, such as mechanoreceptors in the peripheral nervous system. These action potentials travel through the axon of the primary afferent neuron, and the cell body, to a synapse in the superficial dorsal horn of the spinal cord (41). Inputs, from several cells types within the spinal cord, are integrated and passed onto ascending pathways to the brainstem, and subsequently to the thalamus. The thalamus then transmits the signal to higher brain regions involved in the sensory (e.g., the somatosensory cortex) and emotional/affective (e.g., the amygdala and cingulate cortex) aspects of pain. Due to the cross-talk between supra-spinal nociceptive regions, incoming nociceptive signals can be either enhanced or dampened by descending modulatory pathways projecting from the brain to the spinal cord $(40,41)$. The endocannabinoid system is distributed throughout the spinal and supraspinal regions, and thus is able to effectively regulate neurophysiological activities, including affective and nociceptive processing (42).

Clinical studies have shown altered endocannabinoid signaling in patients with chronic pain $(43,44)$ as well as in psychiatric patients $(45,46)$. Certain genetic polymorphisms in $\mathrm{CB} 1$ and $\mathrm{CB} 2$ receptors have been found to be associated with major depression and bipolar disorder $(47,48)$ and resistance to treatment was observed in depression patients having a single nucleotide polymorphism in the CB1 receptor (49). Elevated components of the endocannabinoid system, including plasma 2-AG levels and CB1 and CB2 mRNA levels were observed in the lymphocytes in osteoarthritic patients, who also exhibited a positive correlation between 2-AG levels, pain and depression (50). However, whether these changes are compensatory to tackle the pain in osteoarthritis patients, is not known. Additional studies are necessary to better understand the association of endocannabinoid system and pain and depression. 
Although, to the best of our knowledge, relatively few clinical studies have directly addressed the importance of endocannabinoids in pain-depression interactions, improved muscle and nerve pain by the intake of cannabis has been reported in HIV patients, who exhibited improved symptoms of depression and anxiety (51). In cancer patients, daily adjunctive administration of Cesamet (nabilone, a $\Delta^{9}$-THC analogue) for 30 days was found to improve overall anxiety and pain (52). The therapeutic efficacy of nabilone for pain management and quality of life improvement was demonstrated in a randomized, double-blind, placebo-controlled trial in patients with fibromyalgia (53) (Table I). Similar results were obtained in studies using $\Delta^{9}$-THC (dronabinol) in patients with chronic central neuropathic pain or fibromyalgia (54). The above and other studies (55-57) together indicate that depression/anxiety and pain, when present together in a variety of patients, respond to exogenously administered cannabinoids, although the underlying mechanism remains to be elucidated. It has been demonstrated that $\Delta^{9}$-THC-mediated reductions in pain are associated with enhanced amygdala activity and reduced functional connectivity between the amygdala and somatosensory cortex (58). Thus, the amygdala likely forms the common neural circuit and connecting link between emotional responding and pain. The precise mechanism(s) by which the endocannabinoids influence behavioral/emotional and nociceptive processing remains to be determined. At present, there is considerable evidence involving the endocannabinoid system in eliciting potent effects on neurotransmission, neuroendocrine, and inflammatory processes, which are all known to be deranged in depression and chronic pain.

\section{Conclusions}

Depression and pain co-exist in the majority of patients and often contribute to high mortality. Most patients who suffer from the comorbid depression and pain are not responsive to pharmacological treatments that address either the pain or depression, exacerbating this comorbidity disorder. Cannabinoids present in marijuana are well-known to contain pain and depression, and $\Delta^{9}$-THC, the active ingredient of marijuana, exerts its activity by activating CB1 and CB2 receptors. These receptors are activated by naturally present endocannabinoids, anandamide and 2-AG, which exert cannabinomimetic effects. The endocannabinoid system is involved in eliciting potent effects on neurotransmission, neuroendocrine, and inflammatory processes, which are known to be deranged in depression and chronic pain. Several synthetic cannabinomimetic drugs are being developed to treat pain and depression. However, the precise mode of action of endocannabinoids on different targets in the body and whether their effects on pain and depression follow the same or different pathways, remains to be determined in future studies.

\section{References}

1. Poole H, White S, Blake C, Murphy P and Bramwell R: Depression in chronic pain patients: Prevalence and measurement. Pain Pract 9: 173-180, 2009.

2. Scholich SL, Hallner D, Wittenberg RH, Hasenbring MI and Rusu AC: The relationship between pain, disability, quality of life and cognitive-behavioural factors in chronic back pain. Disabil Rehabil 34: 1993-2000, 2012.
3. Hassett AL, Aquino JK and Ilgen MA: The risk of suicide mortality in chronic pain patients. Curr Pain Headache Rep 18: 436, 2014

4. Hawker GA, Gignac MA, Badley E, Davis AM, French MR, Li Y, Perruccio AV, Power JD, Sale J and Lou W: A longitudinal study to explain the pain-depression link in older adults with osteoarthritis. Arthritis Care Res (Hoboken) 63: 1382-1390, 2011.

5. Emery PC, Wilson KG and Kowal J: Major depressive disorder and sleep disturbance in patients with chronic pain. Pain Res Manag 19: 35-41, 2014.

6. Lin MC, Guo HR, Lu MC, Livneh H, Lai NS and Tsai TY: Increased risk of depression in patients with rheumatoid arthritis: A seven-year population-based cohort study. Clinics (Sao Paulo) 70: 91-96, 2015.

7. Gameroff MJ and Olfson M: Major depressive disorder, somatic pain, and health care costs in an urban primary care practice. J Clin Psychiatry 67: 1232-1239, 2006.

8. Li JX: Pain and depression comorbidity: A preclinical perspective. Behav Brain Res 276: 92-98, 2015.

9. Yalcin I, Barthas F and Barrot M: Emotional consequences of neuropathic pain: Insight from preclinical studies. Neurosci Biobehav Rev 47: 154-164, 2014.

10. Devane WA, Dysarz FA III, Johnson MR, Melvin LS and Howlett AC: Determination and characterization of a cannabinoid receptor in rat brain. Mol Pharmacol 34: 605-613, 1988.

11. Matsuda LA, Lolait SJ, Brownstein MJ, Young AC and Bonner TI: Structure of a cannabinoid receptor and functional expression of the cloned cDNA. Nature 346: 561-564, 1990.

12. Devane WA, Hanus L, Breuer A, Pertwee RG, Stevenson LA, Griffin G, Gibson D, Mandelbaum A, Etinger A and Mechoulam R: Isolation and structure of a brain constituent that binds to the cannabinoid receptor. Science 258: 1946-1949, 1992.

13. Mechoulam R, Ben-Shabat S, Hanus L, Ligumsky M, Kaminski NE, Schatz AR, Gopher A, Almog S, Martin BR, Compton DR, et al: Identification of an endogenous 2-monoglyceride, present in canine gut, that binds to cannabinoid receptors. Biochem Pharmacol 50: 83-90, 1995.

14. Sugiura T, Kondo S, Sukagawa A, Nakane S, Shinoda A, Itoh K, Yamashita A and Waku K: 2-Arachidonoylglycerol: A possible endogenous cannabinoid receptor ligand in brain. Biochem Biophys Res Commun 215: 89-97, 1995.

15. Leggett JD, Aspley S, Beckett SR, D'Antona AM, Kendall DA and Kendall DA: Oleamide is a selective endogenous agonist of rat and human CB1 cannabinoid receptors. Br J Pharmacol 141: 253-262, 2004

16. Porter AC, Sauer JM, Knierman MD, Becker GW, Berna MJ, Bao J, Nomikos GG, Carter P, Bymaster FP, Leese AB, et al: Characterization of a novel endocannabinoid, virodhamine, with antagonist activity at the CB1 receptor. J Pharmacol Exp Ther 301: 1020-1024, 2002.

17. Hanus L, Abu-Lafi S, Fride E, Breuer A, Vogel Z, Shalev DE, Kustanovich I and Mechoulam R: 2-arachidonyl glyceryl ether, an endogenous agonist of the cannabinoid CB1 receptor. Proc Natl Acad Sci USA 98: 3662-3665, 2001.

18. Huang SM, Bisogno T, Trevisani M, Al-Hayani A, De Petrocellis L, Fezza F, Tognetto M, Petros TJ, Krey JF, Chu CJ, et al: An endogenous capsaicin-like substance with high potency at recombinant and native vanilloid VR1 receptors. Proc Natl Acad Sci USA 99: 8400-8405, 2002.

19. Pertwee RG: Targeting the endocannabinoid system with cannabinoid receptor agonists: Pharmacological strategies and therapeutic possibilities. Philos Trans R Soc Lond B Biol Sci 367: 3353-3363, 2012.

20. Starowicz K and Di Marzo V: Non-psychotropic analgesic drugs from the endocannabinoid system: 'magic bullet' or 'multiple-target' strategies? Eur J Pharmacol 716: 41-53, 2013.

21. Sastre-Garriga J, Vila C, Clissold S and Montalban X: THC and CBD oromucosal spray $\left(\right.$ Sativex ${ }^{\circledR}$ ) in the management of spasticity associated with multiple sclerosis. Expert Rev Neurother 11: 627-637, 2011.

22. Wang T, Collet JP, Shapiro S and Ware MA: Adverse effects of medical cannabinoids: A systematic review. CMAJ 178: $1669-1678,2008$

23. Toth C, Mawani S, Brady S, Chan C, Liu C, Mehina E, Garven A, Bestard $\mathbf{J}$ and Korngut L: An enriched-enrolment, randomized withdrawal, flexible-dose, double-blind, placebo-controlled, parallel assignment efficacy study of nabilone as adjuvant in the treatment of diabetic peripheral neuropathic pain. Pain 153: 2073-2082, 2012. 
24. Di Marzo V, Fontana A, Cadas H, Schinelli S, Cimino G, Schwartz JC and Piomelli D: Formation and inactivation of endogenous cannabinoid anandamide in central neurons. Nature 372: 686-691, 1994.

25. Sugiura T, Kondo S, Sukagawa A, Tonegawa T, Nakane S, Yamashita A and Waku K: Enzymatic synthesis of anandamide, an endogenous cannabinoid receptor ligand, through $\mathrm{N}$-acylphosphatidylethanolamine pathway in testis: Involvement of $\mathrm{Ca}(2+)$-dependent transacylase and phosphodiesterase activities. Biochem Biophys Res Commun 218: 113-117, 1996.

26. Cravatt BF, Giang DK, Mayfield SP, Boger DL, Lerner RA and Gilula NB: Molecular characterization of an enzyme that degrades neuromodulatory fatty-acid amides. Nature 384: 83-87, 1996.

27. Blankman JL, Simon GM and Cravatt BF: A comprehensive profile of brain enzymes that hydrolyze the endocannabinoid 2-arachidonoylglycerol. Chem Biol 14: 1347-1356, 2007.

28. Kozak KR, Rowlinson SW and Marnett LJ: Oxygenation of the endocannabinoid, 2-arachidonylglycerol, to glyceryl prostaglandins by cyclooxygenase-2. J Biol Chem 275: 33744-33749, 2000.

29. van der Stelt M, van Kuik JA, Bari M, van Zadelhoff G, Leeflang BR, Veldink GA, Finazzi-Agrò A, Vliegenthart JF and Maccarrone M: Oxygenated metabolites of anandamide and 2-arachidonoylglycerol: Conformational analysis and interaction with cannabinoid receptors, membrane transporter, and fatty acid amide hydrolase. J Med Chem 45: 3709-3720, 2002.

30. Munro S, Thomas KL and Abu-Shaar M: Molecular characterization of a peripheral receptor for cannabinoids. Nature 365: 61-65, 1993.

31. Maldonado R, Valverde O and Berrendero F: Involvement of the endocannabinoid system in drug addiction. Trends Neurosci 29: 225-232, 2006.

32. Pertwee RG: Receptors and channels targeted by synthetic cannabinoid receptor agonists and antagonists. Curr Med Chem 17: 1360-1381, 2010.

33. Kim J and Li Y: Chronic activation of CB2 cannabinoid receptors in the hippocampus increases excitatory synaptic transmission. J Physiol 593: 871-886, 2015.

34. Overton HA, Babbs AJ, Doel SM, Fyfe MC, Gardner LS, Griffin G, Jackson HC, Procter MJ, Rasamison CM, Tang-Christensen $\mathrm{M}$, et al: Deorphanization of a $\mathrm{G}$ protein-coupled receptor for oleoylethanolamide and its use in the discovery of small-molecule hypophagic agents. Cell Metab 3: 167-175, 2006.

35. Sun Y, Alexander SP, Kendall DA and Bennett AJ: Cannabinoids and PPARalpha signalling. Biochem Soc Trans 34: 1095-1097, 2006.

36. Ryberg E, Larsson N, Sjögren S, Hjorth S, Hermansson NO Leonova J, Elebring T, Nilsson K, Drmota T and Greasley PJ: The orphan receptor GPR55 is a novel cannabinoid receptor. Br J Pharmacol 152: 1092-1101, 2007.

37. Fowler CJ: Anandamide uptake explained? Trends Pharmacol Sci 33: 181-185, 2012

38. Jhaveri MD, Richardson D and Chapman V: Endocannabinoid metabolism and uptake: Novel targets for neuropathic and inflammatory pain. Br J Pharmacol 152: 624-632, 2007.

39. Woodward DF, Carling RW, Cornell CL, Fliri HG, Martos JL, Pettit SN, Liang Y and Wang JW: The pharmacology and therapeutic relevance of endocannabinoid derived cyclo-oxygenase (COX)-2 products. Pharmacol Ther 120: 71-80, 2008.

40. Basbaum AI, Bautista DM, Scherrer G and Julius D: Cellular and molecular mechanisms of pain. Cell 139: 267-284, 2009.

41. Todd AJ: Neuronal circuitry for pain processing in the dorsal horn. Nat Rev Neurosci 11: 823-836, 2010.

42. Fitzgibbon M, Finn DP and Roche M: High times for painful blues: The endocannabinoid system in pain-depression comorbidity. Int J Neuropsychopharmacol 19: 19, 2015.
43. Richardson D, Pearson RG, Kurian N, Latif ML, Garle MJ, Barrett DA, Kendall DA, Scammell BE, Reeve AJ and Chapman V: Characterisation of the cannabinoid receptor system in synovial tissue and fluid in patients with osteoarthritis and rheumatoid arthritis. Arthritis Res Ther 10: R43, 2008.

44. Kaufmann I, Hauer D, Huge V, Vogeser M, Campolongo P, Chouker A, Thiel M and Schelling G: Enhanced anandamide plasma levels in patients with complex regional pain syndrome following traumatic injury: A preliminary report. Eur Surg Res 43: 325-329, 2009.

45. Hill MN and Gorzalka BB: Is there a role for the endocannabinoid system in the etiology and treatment of melancholic depression? Behav Pharmacol 16: 333-352, 2005.

46. Koethe D, Llenos IC, Dulay JR, Hoyer C, Torrey EF, Leweke FM and Weis S: Expression of CB1 cannabinoid receptor in the anterior cingulate cortex in schizophrenia, bipolar disorder, and major depression. J Neural Transm Vienna 114: 1055-1063, 2007.

47. Monteleone P, Bifulco M, Maina G, Tortorella A, Gazzerro P, Proto MC, Di Filippo C, Monteleone F, Canestrelli B and Buonerba G: Investigation of CNR1 and FAAH endocannabinoid gene polymorphisms in bipolar disorder and major depression. Pharmacol Res 61: 400-404, 2010

48. Minocci D, Massei J, Martino A, Milianti M, Piz L, Di Bello D, Sbrana A, Martinotti E, Rossi AM and Nieri P: Genetic association between bipolar disorder and 524A $>$ C (Leu133Ile) polymorphism of CNR2 gene, encoding for CB2 cannabinoid receptor. J Affect Disord 134: 427-430, 2011.

49. Domschke K, Dannlowski U, Ohrmann P, Lawford B, Bauer J, Kugel H, Heindel W, Young R, Morris P, Arolt V, et al: Cannabinoid receptor 1 (CNR1) gene: Impact on antidepressant treatment response and emotion processing in major depression. Eur Neuropsychopharmacol 18: 751-759, 2008

50. La Porta C, Bura SA, Llorente-Onaindia J, Pastor A, Navarrete F, García-Gutiérrez MS, De la Torre R, Manzanares J, Monfort J and Maldonado R: Role of the endocannabinoid system in the emotional manifestations of osteoarthritis pain. Pain 156: 2001-2012, 2015 .

51. Woolridge E, Barton S, Samuel J, Osorio J, Dougherty A and Holdcroft A: Cannabis use in HIV for pain and other medical symptoms. J Pain Symptom Manage 29: 358-367, 2005.

52. Maida V, Ennis M, Irani S, Corbo $M$ and Dolzhykov M: Adjunctive nabilone in cancer pain and symptom management: A prospective observational study using propensity scoring. J Support Oncol 6: 119-124, 2008.

53. Skrabek RQ, Galimova L, Ethans K and Perry D: Nabilone for the treatment of pain in fibromyalgia. J Pain 9: 164-173, 2008.

54. Weber J, Schley M, Casutt M, Gerber H, Schuepfer G, Rukwied R, Schleinzer W, Ueberall M and Konrad C: Tetrahydrocannabinol (Delta 9-THC) treatment in chronic central neuropathic pain and fibromyalgia patients: Results of a multicenter survey. Anesthesiol Res Pract 2009: 827290, 2009.

55. Schley M, Legler A, Skopp G, Schmelz M, Konrad C and Rukwied R: Delta-9-THC based monotherapy in fibromyalgia patients on experimentally induced pain, axon reflex flare, and pain relief. Curr Med Res Opin 22: 1269-1276, 2006.

56. Whiting PF, Wolff RF, Deshpande S, Di Nisio M, Duffy S, Hernandez AV, Keurentjes JC, Lang S, Misso K, Ryder S, Schmidlkofer S, Westwood M and Kleijnen J: Cannabinoids for medical use: A systematic review and meta-analysis. JAMA 313: 2456-2473, 2015.

57. Williamson EM and Evans FJ: Cannabinoids in clinical practice. Drugs 60: 1303-1314, 2000

58. Lee MC, Ploner M, Wiech K, Bingel U, Wanigasekera V, Brooks J, Menon DK and Tracey I: Amygdala activity contributes to the dissociative effect of cannabis on pain perception. Pain 154: 124-134, 2013 